\title{
METHOD FOR REDUCING THE COMPUTATIONAL COMPLEXITY OF PROCESSING DISCRETE CYCLIC RANDOM PROCESSES IN DIGITAL DATA ANALYSIS SYSTEMS
}

\author{
Serhii Lupenko; Iaroslav Lytvynenko; Nataliia Stadnyk
}

\author{
Ternopil Ivan Puluj National Technical University, Ternopil, Ukraine
}

\begin{abstract}
Summary. The method of statistical processing of cyclic random processes by reducing them to isomorphic periodic random sequences, which significantly simplifies analytical expressions and formulas for calculations, and also reduces the computational complexity of the tasks of statistical processing and computer simulation (generalization) of cyclical signals in intelligent information systems in medicine, technology and economics, which is especially important for their implementation in portable systems with significantly limited computing capacity is developed in the paper. The example of statistical evaluation of the initial moment function of the first order of cyclic random process of discrete argument using the existing method, and also with the use of the new method of statistical evaluation, based on the procedure of reducing the investigated cyclic random process to isomorphic periodic random sequence, which statistical processing methods are characterized by much less calculations complexity. Isomorphic in terms of order and values, cyclic random processes, in general, differ only in their rhythmic structures (functions of rhythm) and in their totality form an equivalence class. Any class of isomorphic with respect to the order and values of cyclic random processes of a discrete argument, as its subset, contains a subclass of isomorphic with respect to the order and values of periodic random sequences. Based on this fact, the paper developed a method of reducing the statistical processing (estimation, analysis, forecasting) of a cyclic random process of a discrete argument to an isomorphic periodic random sequence. The computational complexity of the known method of statistical estimation of the probabilistic characteristics of a cyclic random process of a discrete argument is investigated and the method of statistical analysis of the probabilistic characteristics of a cyclic random process of a discrete argument developed in this work to the corresponding statistical processing of an isomorphic periodic random sequence is obtained. Examples of statistical estimation of the initial moment function of the first order of a cyclic random process of a discrete argument using the known method are given, as well as with the use of a new method of statistical estimation based on the procedure of reducing the investigated cyclic random process to an isomorphic periodic random sequence, methods of statistical processing of which is characterized by much less computational complexity.
\end{abstract}

Key words: modeling, methods of statistical signals processing, cyclic random process, periodic random sequence, isomorphism.

Statement of the problem. Developing of new and refining of known approaches, models, methods, and hardware to transform, analyze, and predict cyclic signals is a relevant scientific area, since many physical, chemical, technical, biological, economic, political, social processes and phenomena of reality have cyclical, repetitive structure. Typical examples of information systems for analyzing, predicting and diagnosing cyclic signals are computer systems for diagnosing the functional state of the human body, information systems for analyzing and predicting cyclical economic processes, information software and hardware systems for authenticating a person based on his/her biometric dynamic data, energy consumption forecasting automated systems.

The stochastic approach to the simulation of cyclic signals has become widespread in modern information systems for analysis, diagnosis, authentication and forecasting of cyclic signals. Amongst stochastic mathematical models of cyclic signals, stochastic periodic processes (periodic random processes), namely, periodically correlated random process and 
periodically distributed random process with different types of distributions are the most spread [1-9]. The stochastic periodic processes are generalized in [10], where a new mathematical model of cyclic signals has been developed in the form of a cyclic random process, which, as a partial case, includes a periodic random process. In [10-13], the cyclic random process is justified and applied as a mathematical model of various signals with a cyclic space-time structure in medical information diagnostic systems, systems of diagnosis and prediction of the state of the materials coating, as well as in the systems of analysis and forecasting of economic cyclic processes.

Analysis of the available investigations. The works [1,2] provide information on methods of statistical time and spectral analysis of cyclic signals within their model in the form of periodically correlated random process and periodically distributed random process. The stochastic periodicity of the process is the basis for methods of statistical processing of cyclic signals, namely, it allows to average the counts of the investigated cyclic signal implementation taken over a period. Therefore, all these methods, as their parameter, contain the period (or its estimate) of the cyclic signal under study. In researches [10-13], methods of statistical estimation of probabilistic characteristics of cyclic signals, in particular its initial, central and mixed moment functions, as well as multidimensional distribution functions, have been developed on the basis of a cyclic random process. All these methods of statistical estimation of probability characteristics of cyclic signals, contain the function of the rhythm (or its estimation) of the investigated cyclic signal as their parameter function.

The cyclic random process as a mathematical model of cyclic signals within a stochastic approach has a much greater research potential than a stochastic periodic process, for the reason that, firstly, the class of cyclic random processes as a subclass includes a class of stochastic periodic processes, and secondly, unlike stochastic periodic processes, it has the means of taking into account the variability of the of the studied cyclic signal rhythm. However, the methods of handling cyclic random processes in comparison with similar methods for stochastic periodic processes are characterized by much greater computational complexity, which is often an obstacle for their use in portable information systems for analysis, diagnosis and prediction of cyclic signals.

The objective of the work. Considering the abovementioned problem of high computation complexity of statistic evaluation of cyclic random processes probability characteristics, it seems appropriate to move to a simpler method of estimating its characteristics in the computational aspect. This paper deals with the development of statistical processing method of cyclic random processes probabilistic characteristics by cancelling them to isomorphic periodic random sequences, which significantly simplifies the analytical expressions and formulae for calculations, and also reduces the computational complexity in the tasks of statistical processing cyclical signals in intelligent information systems in medicine, technology and economics.

Results of the investigation. In [10], the definitions of a cyclic random process of both discrete and continuous (valid) argument are given, and a vector of cyclic rhythmically related random processes is defined. As modern information systems are predominantly digital, we now describe only the cyclic random process of a discrete argument, which is a model of discretized cyclic signals. Namely, we denote a cyclic random process which is given on a certain probabilistic space with a set of elementary events $\boldsymbol{\Omega}$ and on the discrete set $\mathbf{D}$ - subset $\mathbf{D}=\left\{t_{m l}, m \in \mathbf{Z}, l=1, L, L \geq 2\right\}$ of real numbers, where index $m$ denotes the cycle number of a cyclic random process and index $l$ - count number of discrete random process within its $m$ cycle. 
Definition 1. Discrete random process $\left\{\xi\left(\omega, t_{m l}\right), \omega \in \mathbf{\Omega}, t_{m l} \in \mathbf{D}\right\}$ is referred to as a cyclic discrete random process, if there exists such a discrete function $T\left(t_{m l}, n\right)$ (rhythm function) which satisfies the conditions: 1) $T\left(t_{m l}, n\right)>0$, if $n>0$;2) $T\left(t_{m l}, n\right)=0$, if $n=0$; 3) $T\left(t_{m l}, n\right)<0$, if $n<0$; 4) for any $t_{m_{1} l_{1}} \in \mathbf{D}$ тa $t_{m_{2} l_{2}} \in \mathbf{D}$, for which $t_{m_{2} l_{2}}>t_{m_{1} l_{1}}$, for the function $T\left(t_{m l}, n\right)$ the inequality $t_{m_{1} l_{1}}+T\left(t_{m_{1} l_{1}}, n\right)<t_{m_{2} l_{2}}+T\left(t_{m_{2} l_{2}}, n\right), \forall n \in \mathbf{Z} \quad$ is satisfied; that finite-dimension vectors $\left(\xi\left(\omega, t_{m_{1} l_{1}}\right), \xi\left(\omega, t_{m_{2} l_{2}}\right), \ldots, \xi\left(\omega, t_{m_{k} l_{k}}\right)\right)$ and $\left(\xi\left(\omega, t_{m_{1} l_{1}}+T\left(t_{m_{1} l_{1}}, n\right)\right), \xi\left(\omega, t_{m_{2} l_{2}}+T\left(t_{m_{2} l_{2}}, n\right)\right), \ldots, \xi\left(\omega, t_{m_{k} l_{k}}+T\left(t_{m_{k} l_{k}}, n\right)\right), n \in \mathbf{Z}\right.$, when all integer $k \geq 1$, is stochastically equivalent in a broad sense.

From the definition 1 with necessity, it follows that for cyclic discrete random process that the set of its distribution functions satisfies these equations:

$$
\begin{gathered}
F_{1}\left(x, t_{m l}\right)=F_{1}\left(x, t_{m l}+T\left(t_{m l}, n\right)\right), x \in \mathbf{R}, t_{m l} \in \mathbf{D}, n \in \mathbf{Z}, \ldots, \\
F_{k}\left(x_{1}, \ldots, x_{k}, t_{m_{1} l_{1}}, \ldots, t_{m_{k} l_{k}}\right)= \\
F_{k}\left(x_{1}, \ldots, x_{k}, t_{m_{1} l_{1}}+T\left(t_{m_{1} l_{1}}, n\right), \ldots, t_{m_{k} l_{k}}+T\left(t_{m_{k} l_{k}}, n\right)\right), x_{1}, \ldots, x_{k} \in \mathbf{R}, t_{m_{1} l_{1}}, \ldots, t_{m_{k} l_{k}} \in \mathbf{D}, n \in \mathbf{Z}, k \in \mathbf{N}
\end{gathered}
$$

We define isomorphism with respect to the order and values of cyclic random processes of a discrete argument. Provided we have cyclic random processes $\xi_{1}(\omega, t), \omega \in \boldsymbol{\Omega}, t \in \mathbf{D}$ with the rhythm function $T_{1}(t, n)$ and $\xi_{2}\left(\omega, t^{\prime}\right), \omega \in \mathbf{\Omega}, t \in \mathbf{D}^{\prime}$ with the rhythm function $T_{2}\left(t^{\prime}, n\right)$. The areas of determining $\mathbf{D}$ and $\mathbf{D}^{\prime}$ of these random processes in the general case are different $\left(\mathbf{D} \neq \mathbf{D}^{\prime}\right)$.

Definition 2. Cyclic random process $\xi_{1}(\omega, t), \omega \in \mathbf{\Omega}, t \in \mathbf{D}$ with the rhythm function $T_{1}(t, n)$ and cyclic random process $\xi_{2}\left(\omega, t^{\prime}\right), \omega \in \boldsymbol{\Omega}, t \in \mathbf{D}^{\prime}$ with the rhythm function $T_{2}\left(t^{\prime}, n\right)$, will be called isomorphic in relation to the order and values and say that there exists isomorphism concerning order and values between the cyclic random process, if there are such properties:

1. Isomorphism with respect to order between domains of determination of cyclic random processes (isomorphism between the ordered set of numbers $\mathbf{D}$ and $\mathbf{D}^{\prime}$ ), namely:

a. there is a bijection between $\mathbf{D}$ and $\mathbf{D}^{\prime}$ (indicated: $\mathbf{D} \Leftrightarrow \mathbf{D}^{\prime}$ ), that is to any $t \in \mathbf{D}$ corresponds only one $t^{\prime} \in \mathbf{D}^{\prime}\left(t \rightarrow t^{\prime}\right)$, and any $t^{\prime} \in \mathbf{D}^{\prime}$ is corresponded by only one $t \in \mathbf{D}$ ( $\left.t^{\prime} \rightarrow t\right)$, whilst for any different $t_{1}, t_{2} \in \mathbf{D}$ their shapes $t_{1}^{\prime}, t_{2}^{\prime} \in \mathbf{D}^{\prime}$ are different and vice versa (respectful elements $t \in \mathbf{D}$ and $t^{\prime} \in \mathbf{D}^{\prime}$ will be called bijectively related and indicated $t \leftrightarrow t^{\prime}$ );

b) the type of linear ordering of sets $\mathbf{D}$ and $\mathbf{D}^{\prime}$ is preserved, that is $\forall t_{1}, t_{2} \in \mathbf{D}$, $\exists t_{1}^{\prime}, t_{2}^{\prime} \in \mathbf{D}^{\prime}$, that $t_{1}^{\prime} \leftrightarrow t_{1}, t_{2}^{\prime} \leftrightarrow t_{2}$ and there is there is an order relation $t_{2}^{\prime}>t_{1}^{\prime}$, if $t_{2}>t_{1}$, and vice versa.

2. Isomorphism with respect to order of cyclic random processes $\xi_{1}(\omega, t), \omega \in \boldsymbol{\Omega}, t \in \mathbf{D}$ and $\xi_{2}\left(\omega, t^{\prime}\right), \omega \in \mathbf{\Omega}, t \in \mathbf{D}^{\prime}$, namely:

a) there is a bijection between random processes $\xi_{1}(\omega, t), \omega \in \mathbf{\Omega}, t \in \mathbf{D}$ and $\xi_{2}\left(\omega, t^{\prime}\right), \omega \in \boldsymbol{\Omega}, t \in \mathbf{D}^{\prime}$ (indicated as $\xi_{1}(\omega, t) \Leftrightarrow \xi_{2}\left(\omega, t^{\prime}\right)$ ), that is to any pair $\left(t, \xi_{1}(\omega, t)\right.$ ) from the random process $\xi_{1}(\omega, t), \omega \in \mathbf{\Omega}, t \in \mathbf{D},\left(t^{\prime}, \xi_{2}\left(\omega, t^{\prime}\right)\right)\left(\left(t, \xi_{1}(\omega, t)\right) \rightarrow\left(t^{\prime}, \xi_{2}\left(\omega, t^{\prime}\right)\right)\right)$ from the random process $\xi_{2}\left(\omega, t^{\prime}\right), \omega \in \mathbf{\Omega}, t \in \mathbf{D}^{\prime}$, and to any pair $\left(t^{\prime}, \xi_{2}\left(\omega, t^{\prime}\right)\right)$ from the random process $\xi_{2}\left(\omega, t^{\prime}\right), \omega \in \mathbf{\Omega}, t \in \mathbf{D}^{\prime}$, only one pair is corresponding $\left(t, \xi_{1}(\omega, t)\right)\left(\left(t^{\prime}, \xi_{2}\left(\omega, t^{\prime}\right)\right) \rightarrow\left(t, \xi_{1}(\omega, t)\right)\right)$ from the random process $\xi_{1}(\omega, t), \omega \in \mathbf{\Omega}, t \in \mathbf{D}$, moreover for any different $t_{1}, t_{2} \in \mathbf{D}$ their shapes 
$t_{1}^{\prime}, t_{2}^{\prime} \in \mathbf{W}^{\prime}$ are different and vice versa (corresponding pairs $\left(t, \xi_{1}(\omega, t)\right)$ and $\left(t^{\prime}, \xi_{2}\left(\omega, t^{\prime}\right)\right)$ will be called bijectively related and indicated as: $\left.\left(t, \xi_{1}(\omega, t)\right) \leftrightarrow\left(t^{\prime}, \xi_{2}\left(\omega, t^{\prime}\right)\right)\right)$;

b) cyclic random processes $\xi_{1}(\omega, t), \omega \in \mathbf{\Omega}, t \in \mathbf{D}$ and $\xi_{2}\left(\omega, t^{\prime}\right), \omega \in \mathbf{\Omega}, t \in \mathbf{D}^{\prime}$ are ordered by their determinancy domains, and the ordinal types of random processes coincide with the ordinal types of their determinancy domains $\mathbf{D}$ and $\mathbf{D}^{\prime}$. That is, a set of pairs, $\left\{\left(t, \xi_{1}(\omega, t)\right), t \in \mathbf{D}\right\}$, that forms (represents) a cyclic random process $\xi_{1}(\omega, t), \omega \in \mathbf{\Omega}, t \in \mathbf{D}$ is ordered by the parameter $t$ and has the same order type as a numerical set $\mathbf{D}$, since there always exists bijective reflexion of the determinance domain $\mathbf{D}$ on the random process itself $\xi_{1}(\omega, t), \omega \in \mathbf{\Omega}, t \in \mathbf{D}$, namely, the element $t \in \mathbf{D}$ is corresponded by the only one pair $\left(t, \xi_{1}(\omega, t)\right)$ and vice versa, and moreover, for two different $t_{1}, t_{2} \in \mathbf{D}$ their corresponding pairs $\left(t_{1}, \xi_{1}\left(\omega, t_{1}\right)\right)$ and $\left(t_{2}, \xi_{1}\left(\omega, t_{2}\right)\right)$ are also different. The same occurs in random process $\xi_{2}\left(\omega, t^{\prime}\right), \omega \in \boldsymbol{\Omega}, t \in \mathbf{D}^{\prime}$, i. e. the linear order from the determinance domain $\mathbf{D}^{\prime}$ induces ino the random process itself $\xi_{2}\left(\omega, t^{\prime}\right), \omega \in \mathbf{\Omega}, t \in \mathbf{D}^{\prime}$;

c) there is the same type of ordering cyclic random processes $\xi_{1}(\omega, t), \omega \in \mathbf{\Omega}, t \in \mathbf{D}$ and $\xi_{2}\left(\omega, t^{\prime}\right), \omega \in \boldsymbol{\Omega}, t \in \mathbf{D}^{\prime}$, that is: for any different pairs $\left(t_{1}, \xi_{1}\left(\omega, t_{1}\right)\right)$ and $\left(t_{2}, \xi_{1}\left(\omega, t_{2}\right)\right)$, that are in bijective relation to pairs $\left(t_{1}^{\prime}, \xi_{2}\left(\omega, t_{1}^{\prime}\right)\right)$ and $\left(t_{2}^{\prime}, \xi_{2}\left(\omega, t_{2}^{\prime}\right)\right)\left(\left(t_{1}^{\prime}, \xi_{2}\left(\omega, t_{1}^{\prime}\right)\right) \leftrightarrow\left(\left(t_{1}, \xi_{1}\left(\omega, t_{1}\right)\right)\right)\right.$, $\left.\left(t_{2}^{\prime}, \xi_{2}\left(\omega, t_{2}^{\prime}\right)\right) \leftrightarrow\left(t_{2}, \xi_{1}\left(\omega, t_{2}\right)\right)\right)$, there occur order relations $\left(t_{2}^{\prime}, \xi_{2}\left(\omega, t_{2}^{\prime}\right)\right)>\left(t_{1}^{\prime}, \xi_{2}\left(\omega, t_{1}^{\prime}\right)\right)$ and $\left(t_{2}, \xi_{1}\left(\omega, t_{2}\right)\right)>\left(t_{1}, \xi_{1}\left(\omega, t_{1}\right)\right)$, if $t_{2}^{\prime}>t_{1}^{\prime}$ and $t_{2}>t_{1}\left(t_{1}^{\prime} \leftrightarrow t_{1}, t_{2}^{\prime} \leftrightarrow t_{2}\right)$.

3. There is the equality of the cyclic random processes values $\xi_{1}(\omega, t), \omega \in \mathbf{\Omega}, t \in \mathbf{D}$ and $\xi_{2}\left(\omega, t^{\prime}\right), \omega \in \mathbf{\Omega}, t \in \mathbf{D}^{\prime}$, when their relevant arguments $t \in \mathbf{D}$ and $t^{\prime} \in \mathbf{D}^{\prime}$ are in bijective relation $\left(t \leftrightarrow t^{\prime}\right)$, i. e. taking into account the cyclic property of these random processes, the following processes are present:

$$
\begin{aligned}
& \mathbf{P}\left\{\xi_{1}\left(\omega, t+T_{1}(t, n)\right)=\xi_{2}\left(\omega, t^{\prime}+T_{2}\left(t^{\prime}, n\right)\right)\right\}=1, \\
& t+T_{1}(t, n) \leftrightarrow t^{\prime}+T_{1}\left(t^{\prime}, n\right), t \in \mathbf{D}, t^{\prime} \in \mathbf{D}^{\prime}, n \in \mathbf{Z} .
\end{aligned}
$$

For isomorphic relative to the order and values of cyclic random processes $\xi_{1}(\omega, t), \omega \in \mathbf{\Omega}, t \in \mathbf{D}$ and $\xi_{2}\left(\omega, t^{\prime}\right), \omega \in \mathbf{\Omega}, t \in \mathbf{D}^{\prime}$ there is the equation ( $k$-dimension) of their distribution functions $F_{k_{\xi_{1}}}\left(x_{1}, \ldots, x_{k}, t_{1}, \ldots, t_{k}\right)$ and $F_{k_{\xi_{2}}}\left(x_{1}, \ldots, x_{k}, t_{1}^{\prime}, \ldots, t_{k}^{\prime}\right)$, when corresponding sets of their arguments $t_{i}+T_{1}\left(t_{i}, n\right)$ and $t_{i}^{\prime}+T_{2}\left(t_{i}^{\prime}, n\right), i=1, k, n \in \mathbf{Z}$ are in bijective relation, namely, there occur such relatios:

$$
\begin{gathered}
F_{k_{\xi_{1}}}\left(x_{1}, \ldots, x_{k}, t_{1}+T_{1}\left(t_{1}, n\right), \ldots, t_{k}+T_{1}\left(t_{k}, n\right)\right)=F_{k_{\xi_{2}}}\left(x_{1}, \ldots, x_{k}, t_{1}^{\prime}+T_{2}\left(t_{1}^{\prime}, n\right), \ldots, t_{k}^{\prime}+T_{2}\left(t_{k}^{\prime}, n\right)\right), \\
x_{i} \in \mathbf{R}, t_{i} \in \mathbf{D}, t_{i}^{\prime} \in \mathbf{D}^{\prime}, t_{i}+T_{1}\left(t_{i}, n\right) \leftrightarrow t_{i}^{\prime}+T_{2}\left(t_{i}^{\prime}, n\right), i=\overline{1, k}, k \in \mathbf{N}, n \in \mathbf{Z} .
\end{gathered}
$$

Isomorphic in relation to the order and value cyclic random processes generally differ only by their rhythm structures (rhythm function) and in their totality, form the equivalence class. Any class of isomorphic in relation to the order and value cyclic random processes of the discrete argument, contains a subclass of isomorphic in relation to the order and value periodic random sequences as its subset. According to this fact, it is reasonable to develop a method of summarizing the statistical processing (evaluation, analysis, forecasting) of a cyclic random process of a discrete argument $\xi_{1}(\omega, t), \omega \in \mathbf{\Omega}, t \in \mathbf{D}$ to the corresponding statistical processing 
of its isomorphic periodic random sequence $\xi_{2}(\omega, i), \omega \in \mathbf{\Omega}, i \in \mathbf{Z}$, since processing methods for periodic random sequences are much simpler to be presented in formulae and implemented on digital computer systems, and besides, have lower computational complexity, which is especially important for their implementation in portable systems with significantly limited computing power (low processing speed and memory capacity).

The method of reducing the statistical processing (evaluation, analysis, forecasting) of a cyclic random process of a discrete argument to the corresponding statistical processing of an isomorphic periodic random sequence is to consistently perform such steps:

1) transformation $\omega$-implementation convertion $\xi_{1_{\omega}}\left(t_{m l}\right), \omega \in \mathbf{\Omega}, t_{m l} \in \mathbf{D}$ of the cyclic random process $\xi_{1}\left(\omega, t_{m l}\right), \omega \in \mathbf{\Omega}, t_{m l} \in \mathbf{D}$ into $\omega$-implementation $\xi_{2_{\omega}}(i), i \in \mathbf{Z}$ of its isomorphic in relation to order and value $L$-periodic sequence $\xi_{2}(\omega, i), \omega \in \mathbf{\Omega}, i \in \mathbf{Z}$, by the scale transformation operator action $\mathbf{G}_{y\left(t_{m l}\right)}\{\cdot\}$ with the scale transformation function $y\left(t_{m l}\right)=L \cdot(m-1)+l$;

2) application of known methods of processing periodic random sequences and obtaining their results (statistical point and interval evaluations of certain probabilistic characteristics);

3) obtaining statistical evaluations of the cyclic random process probabilistic characteristics $\xi_{1}\left(\omega, t_{m l}\right), \omega \in \mathbf{\Omega}, t_{m l} \in \mathbf{D}$, by applying the inverse operator to transform the scale to previously obtained relevant statistical evaluations for $L$-periodic random sequence.

Here is an example of a known method for the statistical evaluation of the probabilistic characteristics of a cyclic random process of a discrete argument and the method of reducing statistical processing of a cyclic random process of a discrete argument to the corresponding statistical processing of an isomorphic periodic random sequence, developed in this work. It will be considered that there are $M$ cycles in $L$ readings registered per every cycle of the researched cyclic signal, the mathematic model of which is a cyclic random process $\left\{\xi_{1}\left(\omega, t_{m l}\right), \omega \in \mathbf{\Omega}, t_{m l} \in \mathbf{R}, m=1, M, l=\overline{1, L}\right\} \quad$ (to simplify, we indicate it $\xi_{1}\left(\omega, t_{m l}\right)$ ). Accordingly, $\omega$-implementation will be a mathematical model of the cyclic signal register $\left\{\xi_{1_{\omega}}\left(t_{m l}\right), t_{m l} \in \mathbf{R}, m=1, M, l=1, L\right\}$ (to simplify the further indications, we write $\xi_{1_{\omega}}\left(t_{m l}\right)$ ) of of this cyclic random process of discrete argument. Isomorphic to the investigated discrete process in relation to order and values, $L$-periodic random sequence $\left\{\xi_{2}(\omega, i), \omega \in \mathbf{\Omega}, i=1, M \cdot L\right\}$ (to simplify the further indications, we write $\left.\xi_{2}(\omega, i)\right)$ is obtained by the action of the scale transformation operator $\mathbf{G}_{y\left(t_{m l}\right)}\{\cdot\}$ with the scale transformation function $y\left(t_{m l}\right)=L \cdot(m-1)+l$ on the initial random process $\xi_{1}\left(\omega, t_{m l}\right)$, that is:

$$
\xi_{2}(\omega, i)=\mathbf{G}_{y\left(t_{m l}\right)}\left\{\xi_{1}\left(\omega, t_{m l}\right)\right\},
$$

which is equivalent to such a system of equations:

$$
\left\{\begin{array}{c}
i=y\left(t_{m l}\right)=L \cdot(m-1)+l, m=1, M, l=\overline{1, L}, \\
\xi_{2}(\omega, i)=\xi_{1}\left(\omega, t_{m l}\right), i=1, M \cdot L, t_{m l} \in \mathbf{R} .
\end{array}\right.
$$


By this the scale transformation operator, $M$-cycle $\omega$-implementation $\xi_{1_{\omega}}\left(t_{m l}\right)$ of cyclic random process $\xi_{1}\left(\omega, t_{m l}\right)$ and $M$-cycle $\omega$-implementation $\left\{\xi_{2_{\omega}}(i), i=1, M \cdot L\right\}$ (to simplify the further indications, we write $\left.\xi_{2_{\omega}}(i)\right)$ are connected.

A well-known approach to statistical processing, namely, to the statistical estimation of the probabilistic characteristics of cyclic random processes of a discrete argument, is the approach described in [10]. One method of statistical evaluation with one of the lowest computational complexity (compared to similar methods for evaluation of multidimensional distribution functions and mixed moment functions of many variables) is a method of statistically estimating the initial first-order moment function (mathematical expectation) is a method of statistical evaluation of the initial first-order moment function (mathematical expectation) $m_{\xi}\left(t_{m l}\right)$ of a cyclic random process $\xi_{1}\left(\omega, t_{m l}\right)$. This method makes it possible to obtain the point statistical estimation of cyclic random process mathematic expectation of a discrete argument by its $M$-cycle $\omega$-implementation $\xi_{1_{\omega}}\left(t_{m l}\right)$, which is formally presented as the expression

$$
\hat{m}_{\xi_{1}}\left(t_{1 l}\right)=\frac{1}{M} \sum_{n=0}^{M-1} \xi_{1_{\omega}}\left(t_{1 l}+T\left(t_{1 l}, n\right)\right), l=1, L
$$

A similar formula for calculating the value of a statistical estimate of the initial firstorder moment function (mathematical expectation) of $L$-periodic sequence $\xi_{2}(\omega, i)$, which is isomorphic in relation to the order and values of cyclic process $\xi_{1}\left(\omega, t_{m l}\right)$, is based on the expression

$$
\hat{m}_{\xi_{2}}(l)=\frac{1}{M} \sum_{n=0}^{M-1} \xi_{2_{\omega}}(l+L \cdot n), l=\overline{1, L}
$$

Let us study the computational complexity of the known method of statistical estimating the probabilistic characteristics of a cyclic random process of a discrete argument and the method of statistical processing the probabilistic characteristics of the cyclic random process of a discrete argument developed in this work to the corresponding statistical processing of an isomorphic periodic random sequence. By analyzing formulae (6) and (7), it is possible to single out two groups of calculations. The first group combines operations for the values of implementations $\xi_{1_{\omega}}\left(t_{m l}\right), t_{m l} \in \mathbf{D}$ та $\xi_{2_{\omega}}(i), i=1, M \cdot L$, and the second group of operations on values taken by arguments of these $\omega$-implementations. Since $L$-periodic random sequence $\xi_{2}(\omega, i)$ and cyclic random process $\xi_{1}\left(\omega, t_{m l}\right)$ have the same values resulting from their isomorphism related to their order and values and the structures of operation procedures on the realization values according to formulae (6) and (7) are identical, then the first group of calculation operations and their relevant computation complexity according to the formula (6) is identical to the first group of operations and computational complexity due to the formula (7). That is, the reduction method for these groups of operations does not give any advantages from the position of reducing the computational complexity of statistical estimation methods. However, for the second group of operations, application of the reduction method will male it possible to significantly decrease the computational complexity of the process of estimating the probability characteristics of the cyclic random processes of the discrete argument. Let us demonstrate this. 
Analyzing the formula (6), we can see that to get the estimation of the mathematic expectation of the cyclic random process $\xi_{1}\left(\omega, t_{m l}\right)$, it is necessary to previously calculate the rhythm function $T\left(t_{m l}, n\right)$, which is the function of two arguments, namely, of argument $t_{m l}$, that takes its values from the set of real numbers and the integer argument $n$, whilst the first argument, in turn, is also a function of two integer arguments $m$ and $l$. Formula (7) looks much simpler than the formula (6), since it does not require calculating the value of the argument $t_{m l}$ and the value of the discrete rhythm function $T\left(t_{m l}, n\right)$, and to select the value of implementation $\xi_{\omega_{\omega}}(i)$ of the periodic random sequence it only two arithmetic operations (multiplication and addition operations) over integers $l, L$ and $n$ have to be performed.

The computational complexity of the second group of operations (submethod) of the method of statistical estimation of probabilistic characteristics of cyclic random process and periodic random sequence as a certain function $C(L, M)$ of the parameters $L$ and $M$ is presented. The parameters of the computational complexity of the subtask (submethod) under study determine its dimension, as well as specify the accuracy and resolution of the method of estimating probabilistic characteristics, namely, parameter $L$ specifies resolution (the number of statistic counts per cycle), and parameter $M$ - the accuracy (statistics volume) of the probability characteristics estimation method. First write down the function $C(L, M)$ for the second subtask of the problem of estimating the mathematical expectation of a periodic random sequence $\xi_{2}(\omega, i)$.

As the second subtask (the subtask of calculating integer arguments of a periodic random sequence) is brought to completing $L \cdot M$ arithmetic operations of integer multiplication of two numbers $L$ and $M$ and adding an integer to their product $l$, then the computational complexity function of this subtask can be represented as follows:

$$
C_{2}(L, M)=2 \cdot L \cdot M
$$

As it is seem from the formula (8), when $L$ and $M$ increase, computational complexity will increase linearly for each of the parameters. In function (8), the computational complexity of performing the arithmetic addition and multiplication operations is assumed to be equal (although in practice they are different), since taking into account their differences does not affect the reduction of computational complexity due to the use of the method of reduction compared to the known method.

The function of computational complexity of the second subtask (the subtask of calculating real value arguments of a cyclic random process of a discrete argument) is given as the sum of three components:

$$
C_{1}(L, M)=C_{1}^{1}(L, M)+C_{1}^{2}(L, M)+C_{1}^{3}(L, M),
$$

where the first component $C_{1}^{1}(L, M)$ determines the number of operations for selecting argument values $t_{1 l}$ from the one-dimensional array $\left\{t_{1 l}, l=1, L\right\}$. This component does not depend on the number of cyclic signal cycles recorded $\left(C_{1}^{1}(L, M)=C_{1}^{1}(L)\right)$, but only on the number of values for its implementation in one cycle and its value is $C_{1}^{1}(L, M)=C_{1}^{1}(L)=L$; the srcond component $C_{1}^{2}(L, M)$ determines the number of operations to calculate the value of a discrete rhythm function $T\left(t_{1 l}, n\right)$ which is the function of two arguments, namely, the 
argument $t_{1 l}$ gaining its values from the set of real numbers and integer argument $n$. Function $C_{1}^{2}(L, M)$ looks $C_{1}^{2}(L, M)=M \cdot L$. The third component $C_{1}^{2}(L, M)$ determines the number of arithmetic operations when calculating the values of the implementation arguments $\xi_{1_{\omega}}\left(t_{m l}\right)$ of the cyclic random process $\xi_{1}\left(\omega, t_{m l}\right)$ and looks $C_{1}^{3}(L, M)=2 \cdot L \cdot M$, i. e. is equal to the computational complexity function for the formula (5). Thus, the computational function of the second subtask of calculating real value arguments of a cyclic random process looks as follows:

$$
C_{1}(L, M)=L+L \cdot M+2 \cdot L \cdot M=3 \cdot L \cdot M+L
$$

Graphs of cross-sections of computational complexity functions $C_{1}(L, M)$ and $C_{2}(L, M)$ are presented at figures 1 and 2 .

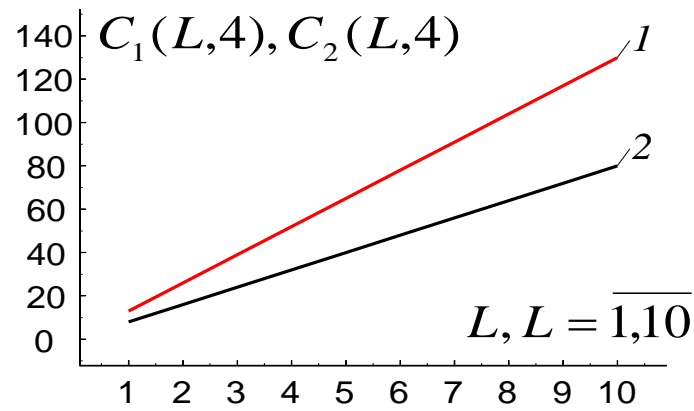

a)

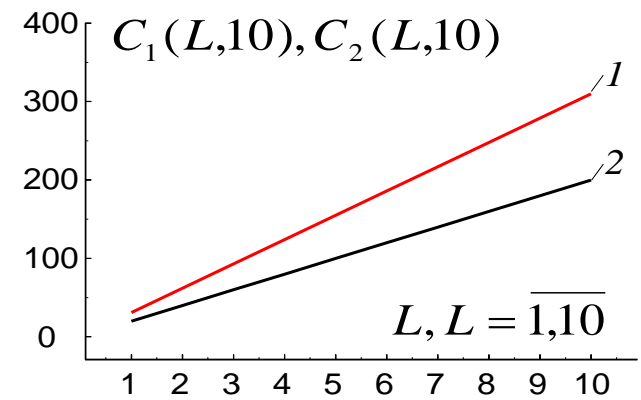

b)

Figure 1. Graphs of cross-sections of computational complexity functions $C_{1}(L, M)$ and $C_{2}(L, M)$ from number $L$ counts of the cyclic signal on one of its cycles for the existing and new methods of statistical estimation of the initial moment function of the first order: a) at $M=4$ and b) at $M=10$

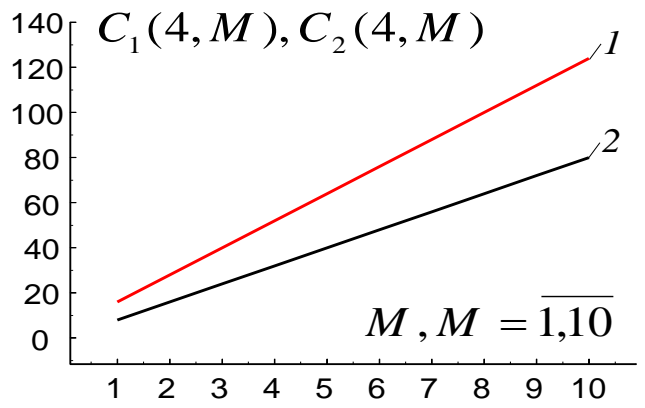

a)

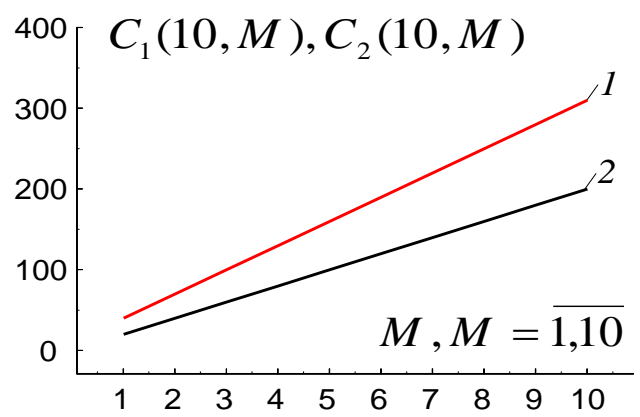

b)

Figure 2. Graphs of cross-sections of computational complexity functions $C_{1}(L, M)$ and $C_{2}(L, M)$ from number $M$ registered cycles of the cyclic signal for existing and new methods of statistical estimation of the initial moment function of the first order: a) at $L=4$ and b) at $L=10$

As we can see, the function of computational complexity, namely, the number of operations (arithmetic and array read operations) for the new method is smaller than the known one, to be precisecyclic random, when applying the developed method to reduce the cyclic random process of a discrete argument to an isomorphic periodic random sequence, the reduction of the computational complexity function for the second subtask is:

$$
\Delta C(L, M)=C_{1}(L, M)-C_{2}(L, M)=3 \cdot L \cdot M+L-2 \cdot L \cdot M=L \cdot M+L=L \cdot(M+1),
$$

that is, it decreases slightly more than twice. 
Here is an example of using a newly developed method to solve the problem of statistical estimation of the probabilistic characteristics of an electrocardio signal, furthermore, only to solve the problem of the statistical point estimation of its initial instantaneous first-order function (mathematical expectation) by its long multi-cycle register (electrocardiogram), which is shown in the figure 3 (a) and the model of which is the cyclic random component of a discrete argument $\xi_{1}\left(\omega, t_{m l}\right)$. The graph of the rhythm function evaluation $T\left(t_{m l}, n\right)$ (when $n=1$ ) of the registered electro cardiac signal the model of which is the cyclic random process of the discrete argument shown in Figure 3 (b).

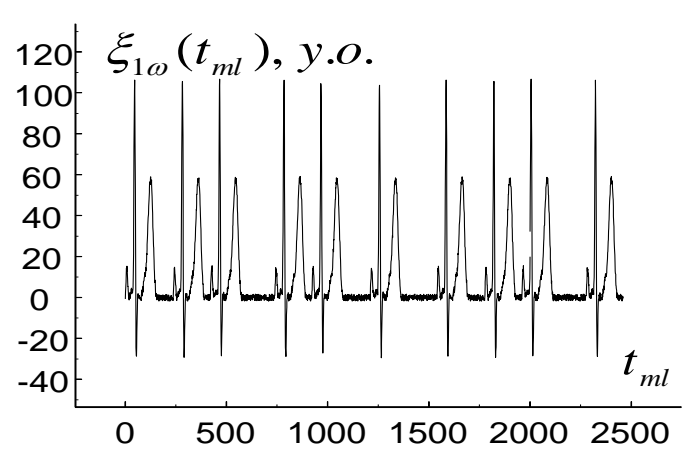

a)

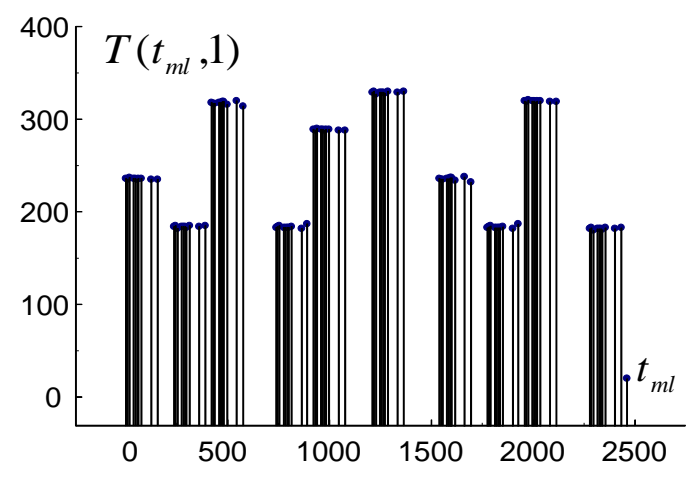

b)

Figure 3. Graphs: a) several cycles of the registered implementation of electrocardio signal; b) evaluation of rhythm function $T\left(t_{m l}, n\right)$ (at $n=1$ ) of the registered electrocardio signal

Figure 4 shows (a) implementation $\xi_{2_{\omega}}(i) \quad L$-periodic random sequence $\xi_{2}(\omega, i)$, obtained according to the formulae (3) and (4) on implementation $\xi_{1_{\omega}}\left(t_{m l}\right)$ (on electrocardiogram) of a cyclic random process $\xi_{1}\left(\omega, t_{m l}\right)$. The graph of rhythm evaluation function $T\left(t_{m l}, n\right)$ (when $\left.n=1\right) L$-periodic random sequence, obtained from electrocardiac signal by scale conversion operator action, is presented on Figure 4 (b).

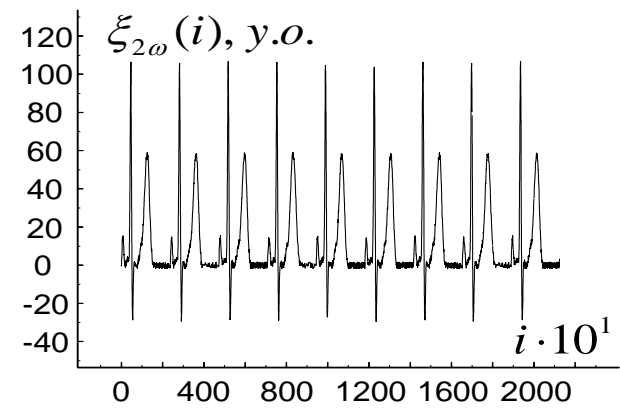

a)

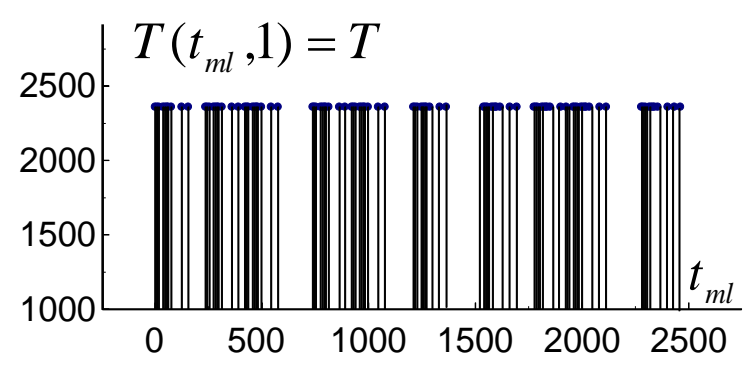

b)

Figure 4. Graphs: a) several cycles of implementation $L$-periodic random sequence, obtained from the electrocardiogram, by scale conversion operator action on it;

b) evaluation of rhythm function $T\left(t_{m l}, n\right)$ (at $\left.n=1\right) L$-periodic random sequence

In Figure 5 (a) the evaluation $\hat{m}_{\xi_{2}}(i)$ of the momentary function of the first order (mathematic expectation) $L$-periodic random sequence $\xi_{2}(\omega, i)$, which is calculated by 
formula (5), is presented. Figure 5 (b) presents the evaluation $\hat{m}_{\xi_{1}}\left(t_{m l}\right)$ of the initial momentary function of the first order (mathematic expectation) of the electrocardio signal, calculated by formula (6).

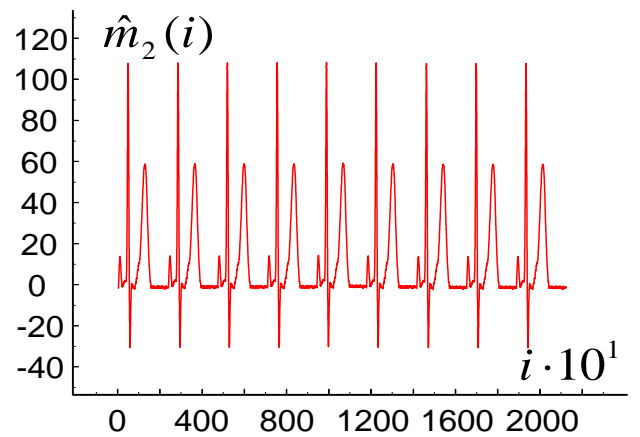

a)

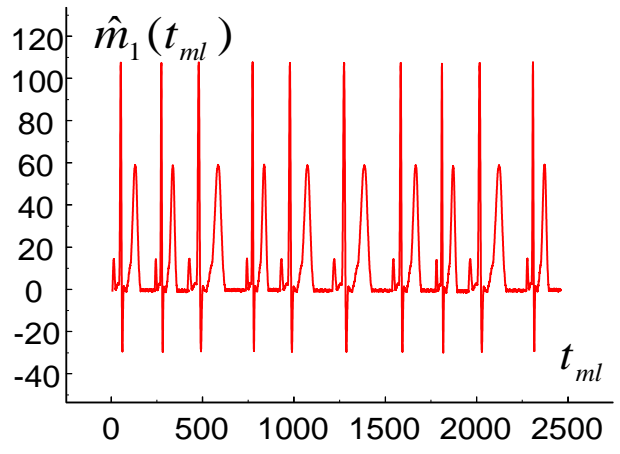

b)

Figure 5. Graphs: a) several evaluation cycles $\hat{m}_{\xi_{2}}(i)$ of the initial momentary function of the first order $L$-periodic random sequences $\xi_{2}(\omega, i)$; b) several initial cycles of the initial momentary function of the first order of the electrocardio signal

It should be noted that in the paper, the simplest method of statistical estimation of the probabilistic characteristics of cyclic random processes, namely, the method of estimating its one-dimensional initial momentary function, was considered. If consider the methods of evaluating mixed moment functions of many arguments, where their computational complexities are reasonably higher than in our case, the decrease of the computational complexity function due to the application of the method of reduction will be much more noticeable. In particular, by analogy with the results obtained, it is possible to demonstrate a significant reduction in the computational complexity of methods for statistical estimation of the correlation and covariance functions of a cyclic random process of a discrete argument, which are often encountered in problems of spectral-correlation analysis of cyclic signals.

Conclusions. The method of statistical processing of cyclic random processes by reducing them to isomorphic periodic random sequences is developed in the work. This technique significantly simplifies the analytical expressions and formulas for calculations as well as reduces the computational complexity in the tasks of statistical processing and computer simulation (generation) of cyclic signals in intelligent information systems in medicine, technology and economics. This is especially important for their implementation in portable systems with significantly limited computing power. In the future studies, it is promising to extend the developed method of spectral analysis and computer simulation of cyclic random processes.

\section{References}

1. Gardner W. A., Napolitano A., Paura L. Cyclostationarity: Half a century of research. Signal Processing. 2005. № 86 (2006). P. 639-697. https://doi.org/10.1016/j.sigpro.2005.06.016

2. Hurd H. L. Periodically Correlated Random Sequences: Spectral Theory and Practice. The University of North Carolina at Chapel Hill Hampton University.

3. Kochel P. Periodically stationary Markovian decision models. Elektron. Informationsverarb. Kybernet. 1980. No. 16. P. 553-567. [In German].

4. Nematollahi A. R., Soltani A. R. Discrete time periodically correlated Markov processes. Probability and Mathematical Statistics. 2000. No. 20 (1). P. 127-140. 
Method for reducing the computational complexity of processing discrete cyclic random processes in digital data analysis systems

5. Ghysels E., McCulloch R. E., Tsay R. S. Bayesian Inference for a General Class of Periodic Markov Switching Models. 1993.

6. Ghysels E. On the Periodic Structure of the Business Cycle. Cowles Foundation, Yale Universiti. 1992. No. 1028.

7. Bittanti S., Lorito F., Strada S. Markovian representations of cyclostationary processes, in: L. Gerencser, P. E. Caines (Eds.). Topics in Stochastic Systems: Modelling, Estimation and Adaptive Control. Springer. 1991. Vol. 161. P. 31-46. https://doi.org/10.1007/BFb0009297

8. Lupenko S. A., Osukhivska H. M., Lutsyk N. S., Stadnyk N. B., Zozulia A. M., Shablii N. R. The comparative analysis of mathematical models of cyclic signals structure and processes. Scientific journal of the Ternopil National Technical University. No. 2 (82). 2016. ISSN 1727-7108. P. 115-127.

9. Lytvynenko I. V. Method of segmentation of determined cyclic signals for the problems related to their processing and modeling. Scientific journal of the Ternopil National Technical University. No. 4 (88). 2017. ISSN: 2522-4433. P. 153-169. https://doi.org/10.33108/visnyk_tntu2017.04.153

10. Lupenko S. A. Theoretical bases of modeling and processing of cyclic signals in information systems: scientific monograph. Lviv: Magnolia Publishing House, 2016. 344 p.

11. Lupenko S., Orobchuk O., Stadnik N., Zozulya A. Modeling and signals processing using cyclic random functions: 13th IEEE International Scientific and Technical Conference on Computer Sciences and Information Technologies (CSIT) (Lviv, September 11-14.). Lviv, 2018. T. 1. P. 360-363. ISBN 978-15386-6463-6. IEEE Catalog Number: CFP18D36-PRT.

12. Lupenko S., Lutsyk N., Lapusta Y. Cyclic Linear Random Process As A Mathematical Model Of Cyclic Signals. Acta mechanica et automatica. 2015. № 9 (4). P. 219-224. https://doi.org/10.1515/ama-2015-0035

13. Lytvynenko Y., Lupenko S., Maruschak P. Analysis of multiple cracking of nano-coatings as cyclic random process. Autometry. Novosibirsk: Siberian Branch of the Russian Academy of Sciences, 2013. № 2. P. 68-75. https://doi.org/10.3103/S8756699013020088

\section{Список використаної літератури}

1. Gardner W. A., Napolitano A., Paura L. Cyclostationarity: Half a century of research. Signal Processing. 2005. № 86 (2006). P. 639-697. https://doi.org/10.1016/j.sigpro.2005.06.016

2. Hurd H. L. Periodically Correlated Random Sequences: Spectral Theory and Practice. The University of North Carolina at Chapel Hill Hampton University.

3. Kochel P. Periodically stationary Markovian decision models. Elektron. Informationsverarb. Kybernet. 1980. No. 16. P. 553-567. [In German].

4. Nematollahi A. R., Soltani A. R. Discrete time periodically correlated Markov processes. Probability and Mathematical Statistics. 2000. No. 20 (1). P. 127-140.

5. Ghysels E., McCulloch R. E., Tsay R. S. Bayesian Inference for a General Class of Periodic Markov Switching Models. 1993.

6. Ghysels E. On the Periodic Structure of the Business Cycle. Cowles Foundation, Yale Universiti. 1992. No. 1028.

7. Bittanti S., Lorito F., Strada S. Markovian representations of cyclostationary processes, in: L. Gerencser, P. E. Caines (Eds.). Topics in Stochastic Systems: Modelling, Estimation and Adaptive Control. Springer. 1991. Vol. 161. P. 31-46. https://doi.org/10.1007/BFb0009297

8. Lupenko S. A., Osukhivska H. M., Lutsyk N. S., Stadnyk N. B., Zozulia A. M., Shablii N. R. The comparative analysis of mathematical models of cyclic signals structure and processes. Scientific journal of the Ternopil National Technical University. No. 2 (82). 2016. ISSN 1727-7108. P. 115-127.

9. Lytvynenko I. V. Method of segmentation of determined cyclic signals for the problems related to their processing and modeling. Scientific journal of the Ternopil National Technical University. No. 4 (88). 2017. ISSN: 2522-4433. P. 153-169. https://doi.org/10.33108/visnyk_tntu2017.04.153

10. Лупенко С. А. Теоретичні основи моделювання та обробки циклічних сигналів в інформаційних системах: наукова монографія. Львів: Магнолія, 2006. 344 с.

11. Lupenko S., Orobchuk O., Stadnik N., Zozulya A. Modeling and signals processing using cyclic random functions: 13th IEEE International Scientific and Technical Conference on Computer Sciences and Information Technologies (CSIT) (Lviv, September 11-14.). Lviv, 2018. T. 1. P. 360-363. ISBN 978-15386-6463-6. IEEE Catalog Number: CFP18D36-PRT.

12. Lupenko S., Lutsyk N., Lapusta Y. Cyclic Linear Random Process As A Mathematical Model Of Cyclic Signals. Acta mechanica et automatica. 2015. № 9 (4). P. 219-224. https://doi.org/10.1515/ama-2015-0035

13. Литвиненко Я., Лупенко С., Марущак П. Анализ множественного растрескивания нанопокрытий как циклический случайный процесс. Новосибирск: Сибирское отделение РАН, 2013. № 2. C. 68-75. https://doi.org/10.3103/S8756699013020088 
УДК 519.218

\title{
МЕТОД ЗМЕНШЕННЯ ОБЧИСЛЮВАЛЬНОЇ СКЛАДНОСТІ ОПРАЦЮВАННЯ ДИСКРЕТНИХ ЦИКЛІЧНИХ ВИПАДКОВИХ ПРОЦЕСІВ У ЦИФРОВИХ СИСТЕМАХ АНАЛІЗУ ДАНИХ
}

\section{Сергій Лупенко; Ярослав Литвиненко; Наталія Стадник}

\author{
Тернопільський національний технічний університет імені Івана Пулюя, \\ Тернопіль, Україна
}

\begin{abstract}
Резюме. Розроблено метод статистичного опрацчювання циклічних випадкових проиесів, иляхом зведення їх до ізоморфних ним періодичних випадкових послідовностей, шо суттєво спрощує аналітичні вирази та формули для розрахунків, а також зменшує обчислювальну складність у задачах статистичного опраџювання та комп'ютерної імітації (генерування) цииклічних сигналів у інтелектуалізованих інформаційних системах у медищині, техніці та економіці, щчо особливо важливо для їх реалізації у портативних системах із суттєво обмеженими обчислювальними потужностями. Ізоморфні відносно порядку та значень циклічні випадкові процеси, загалом, відрізняються лише свойми ритмічними структурами (функціями ритму) і у своїй сукупності формують клас еквівалентності. Будьякий клас ізоморфних відносно порядку та значень ичиклічних випадкових процесів дискретного аргументу як свою підмножину містить підклас ізоморфних відносно порядку та значень періодичних випадкових послідовностей. Виходячи із иього факту, в роботі був розроблений метод зведення статистичного опрацъювання (оичнювання, аналізу, прогнозування) ичклічного випадкового проиесу дискретного аргументу до ізоморфної йому періодичної випадкової послідовності. Проведено дослідження обчислювальної складності відомого методу статистичного оиінювання ймовірнісних характеристик цииклічного випадкового прочеесу дискретного аргументу та розробленого методу зведення статистичного опрацювання ймовірнісних характеристик ичилічного випадкового проиесу дискретного аргументу до відповідного статистичного опрацювання ізоморфної йому періодичної випадкової послідовності. Наведено приклади статистичного очінювання початкової моментної функиії першого порядку ичклічного випадкового процесу дискретного аргументу із використанням відомого методу, а також із застосуванням нового методу статистичного оцінювання, щзо грунтується на процедурі зведення досліджуваного ичиклічного випадкового процесу до ізоморфної йому періодичної випадкової послідовності, методи статистичного опрацювання якої характеризується значно меншою обчислювальною складністю.
\end{abstract}

Ключові слова: моделювання, методи статистичного опрацฺювання сигналів, ичиклічний випадковий процес, періодична випадкова послідовність, ізоморфізм. 